\title{
Supplementing Western Perspectives of Learner-Centered Instruction With a Daoist Approach Towards Authentic Power Sharing in the Classroom
}

\author{
David M. Jeffrey ${ }^{1}$, Renee M. Clark ${ }^{2}$ \\ ${ }^{1}$ Sichuan University-Pittsburgh Institute (SCUPI), China \\ ${ }^{2}$ University of Pittsburgh, USA \\ Correspondence: Renee M. Clark, University of Pittsburgh, USA.
}

Received: January 3, 2019

doi:10.11114/ijce.v2i1.4016
Online Published: January 31, 2019

URL: https://doi.org/10.11114/ijce.v2i1.4016

\begin{abstract}
Learner-centered teaching (LCT) has one main focus - learners and learning! With learner-centered teaching, the traditional roles of the instructor and learners change. In this paper, we draw various parallels between learner-centered instruction and ancient Chinese wisdom based on Daoist perspectives to further promote and support learner-centered teaching among instructors, in particular college instructors. Daoist wisdom is a philosophy based on living in peace and harmony with the way everything is in nature, and it encourages sharing of power with students, which ultimately engenders trust. This paper will present and discuss the key characteristics of learner-centered instruction alongside ancient Daoist perspectives that align with and promote and support this type of instruction. These learner-centered characteristics include 1) the instructor as a facilitator of learning, 2) sharing of power and control with learners, 3) student participation and responsibility for learning, 4) collaboration among learners, 5) higher-order skills instruction and development, and 6) evaluation for learning purposes. This paper is organized based on these interrelated and interdependent characteristics of LCT and their relationship to ancient Daoist perspectives, which can support instructors in applying learner-centered instructional methods.
\end{abstract}

Keywords: Daoism, learner centered instruction, learner centered teaching, classroom sharing of power and control, Chinese

\section{Introduction}

Learner-centered teaching (LCT) has one main focus - learners and learning! LCT centers on optimizing learning and focuses on what is being learned, how learning is occurring, and whether knowledge is being applied (Doyle, 2011; Weimer, 2013, Weimer, 2002).

This is in contrast to teacher-centered instruction, where the focus tends to be on content delivery and lecturing, with the instructor often working the hardest and/or doing the bulk of the tasks in the classroom (Doyle, 2011; Minter, 2011; Weimer, 2013). With learner-centered teaching, the traditional roles of the instructor and learners change, and this leads to enhanced learning and development (Weimer, 2013). Learner-centered perspectives also encourage genuine power sharing between teachers and learners and the responsible placement of some control in the hands of the students over their learning processes (Blumberg, 2009; Schweisfurth, 2013; Weimer, 2013). Importantly, among those who do educational and neuroscience/cognitive psychology research, there is agreement that learner-centered instruction is more effective than lecture-based instruction (where the teacher does most of the work) in terms of promoting problem solving and higher-level thinking skills as well as learning in general (Doyle, 2011; Felder, 2011). However, there can be challenges in the changing of these traditional roles. Unfortunately, some instructors have a fear of letting go of their "control," believing it will result in rebelliousness and disorder in the classroom (Schweisfurth, 2013). From a Daoist perspective, however, instructors should not be "authoritarian," but rather should work towards mutual respect and the sharing of ideas and power with students (Nagel, 1994). In this paper, we present various parallels between learner-centered instruction and Chinese Daoist perspectives as found in the Daode Jing, or Tao Te Ching, to promote and further support learner-centered teaching in college classrooms and beyond.

In her book The Tao of Teaching, Nagel identified the relationship between the ancient concepts on which her book are 
based (i.e., Taoism) and more-recent ideas for learner-centered practices (Nagel, 1994). In fact, Nagel states, “...'real' teachers enact Taoist philosophical concepts in their daily work." (Nagel, 1994, pp.2). Daoist wisdom is a philosophy based on living in peace and harmony with the way everything is in nature. It is one of the three main Chinese philosophies, alongside Confucianism and Buddhism, which are collectively known as the Three Teachings. The Daoist philosophy sees everything as an integral part of nature. The Daoist way of being is based in nature, of which humans are an inseparable part.

The choice of applying Daoist philosophy in this article to supplement Western learner-centered perspectives, rather than applying Confucianism or Buddhism, was mainly determined by the author's research background in applying Daoism with teacher diary studies based on the Daode jing to classroom instruction (Jeffrey, 2015). In addition, the author recently completed further Daoist reflections based on another recently published teacher diary study centered on the Daoist classic known as the Zhuangzi (Jeffrey, 2019). Thus, the prior experience of the author in using introspective diary studies within educational practices more closely aligned with Daoism, versus Confucianism or Buddhism.

Teacher diary studies are first-person, written interpretations of the experiences of educators both inside and outside the classroom that are examined for recurring patterns to gain insights that facilitate awareness. Howell-Richardson and Parkinson (1988); Bailey (1990); Nunan (1992); Jarvis (1992); Bell (1993); Richards and Lockhart (1996); and Henderson, Morris and Fitz-Gibbon (1987) are notable linguists who have recognized the many benefits of teacher diary studies through their use of them for developing insight and self-awareness using authentic self-reflection. The author's diary studies on applying Daoism paved the way for a more effortless practice of his teaching as both a structured discipline as well as a formless work of art that balanced mutually-dependent polarities. The result was an infusion of harmony among unanticipated classroom circumstances with minimum effort. Contentment became shared between instructors and learners, and this in turn enhanced the effectiveness of the learning environment.

In addition, teachers such as Doerger (2004), Flowers (1998), and Nagel (1994) have adapted Daoism to their teaching styles (though not with teacher diary studies), opening the way for flexibility versus rigidity, gentleness versus strictness, and patience versus impulsiveness. This paper will present and discuss the key characteristics of Western learner-centered instruction alongside ancient Daoist perspectives based on the Dao which, although ineffable, is "an integral part of nature and the greater universe, which functions in perfect harmony and is fundamentally good" (Kohn, 2009, p. 365).

From a Western perspective, noted educator and author Maryellen Weimer proposed several key characteristics that make teaching and learning "learner-centered," and these characteristics do indeed focus on the learner (Weimer, 2013; Weimer, 2018 February 14; Weimer, 2012 August 8; Weimer, 2002). These characteristics include the following: 1) the instructor as a facilitator of learning, 2) sharing of power and control with learners, 3) student participation and responsibility for learning, 4) collaboration among learners, 5) higher-order skills instruction and development, and 6) evaluation for learning purposes. This paper is organized on these interrelated and interdependent characteristics of LCT and their relationship to ancient Daoist perspectives, which can encourage instructors in applying learner-centered instructional methods.

\section{Key Characteristics of Learner-Centered Instruction and Relationship to Daoism}

\subsection{The Instructor as a Facilitator of Learning}

Lecture-oriented, teacher-centered instruction has been described as authoritarian in nature (Doyle, 2011). However, in the learner-centered (LC) classroom, the role of the teacher is that of a guide, facilitator of learning and student construction of knowledge, creator of experiences, and instructional designer, versus the main "performer of learning tasks" or "disseminator of content information." (Blumberg, 2009; Doyle, 2011; Walczyk \& Ramsey, 2003; Weimer, 2013). This entails instructors working more directly with and interacting with learners (Blumberg, 2009; Chickering \& Gamson, 1999; Walczyk \& Ramsey, 2003; Weimer, 2013). In addition, activity and attention are focused on what the learners are doing and learning - versus on what the instructor is doing (Weimer, 2013; Weimer, 2002). This allows the instructor to adjust the teaching as needed (Weimer, 2013). Another important and related role for the instructor in a LC classroom is the creation and maintenance of a classroom environment that promotes learning, with the instructor relying on learners to assist in this as well (Blumberg, 2009;Weimer, 2013).

Complementing these Western perspectives, Daoist perspectives entail a combination of process-orientated learning that can be illustrated by the following Daoist-inspired sayings: "I hear, I forget. I see, I remember. I do, I understand," and "Give people fish and you feed for them for a day, but teach people how to fish and you feed them for a lifetime" (Nagel, 1994). As embodied in such ancient sayings, the sole role of a teacher should not be that of disseminator of knowledge; likewise, learner-centered teaching (LCT) does not revolve around authoritative transmission of knowledge from instructor to student (Cornelius-White \& Harbaugh, 2010; Schweisfurth, 2013). Rather, LCT acknowledges that learners are also a source of the learning, which is centered with them (Schweisfurth, 2013). By going back into ancient history 
and considering Daoist wisdom, it can serve as a support to contemporary Western ideas of learner-centered classrooms.

The writings of Lao Tzu in the Daode Jing, or Tao Te Ching, which is the ancient Chinese book of wisdom on which Daoism is based, are especially relevant to teaching and teachers (Nagel, 1994). Lao Tzu was influenced by the yin and yang philosophers who preceded him (Nagel, 1994). The concepts of yin and yang permeate throughout all of Chinese philosophy, dating back at least 5,000 years in recorded history. Yin represents the subtler nature of the cosmos (e.g., the indirect, the feminine, the night and the moon), whereas yang represents the bolder nature of the cosmos (e.g., the direct, the masculine, the day and the sun) (Kohn, 2009). One can begin to recognize examples of yang-oriented direct instruction (e.g., teaching grammar structures) versus yin-oriented indirect instruction (e.g., inspiring creativity and insights) (Jeffrey, 2015). Facilitative teaching is an integrated process of balancing the directness of dominant yang with the subtler yin. Neither dominance nor receptiveness can exist in exclusion of the other, given that they rely upon each other. Yin and yang are not dualistically opposed entities, as in the Western notion of "black" as the opposite of "white." Rather, taking a yin and yang perspective, black and white are actually in a complementary relationship with one another such that each not only defines itself in relation to the other but also depends on its existence by virtue of the other (Kohn, 2009; Serran-Pagan y Fuentes, 2017). This perspective of the complementary relationship of yin and yang can help instructors see themselves and their learners less as separate entities and more as mutually-dependent entities that share the same objective, which is academic excellence (Jeffrey, 2018).

The facilitation of learning in a learner-centered classroom can be compared to the delicate balance involved in combining the directness of yang-orientated academic approaches aimed at content delivery with the indirectness of yin-oriented approaches aimed at nurturing students and promoting insights, awareness, and creativity. Knowing how to apply both of these processes simultaneously, and in what measure, depends on developing an intuitive sensitivity to their ever-changing relation to each other and adapting to the uniqueness of each situation. However, learning to blend this directness with the indirectness can enhance instructional effectiveness by promoting a creative learning atmosphere. The concepts of yin and yang can encourage instructors to be open to alternative approaches, depending on the particular situation (Jeffrey, 2015). From a Daoist perspective, since white exists by virtue of black and vice versa, the mutuality gives rise to "shades of grey." While this grey area may be uncomfortable from a Western perspective, it is considered an essential, and even comforting, element that binds all the yin and yang dimensions of the cosmos. By applying this all-embracing way of thinking, the classroom can become a world in which learning is facilitated in a mutually interdependent manner, with the practice of yang-oriented direct instruction as well as yin-oriented indirect instruction. True learner-centered facilitation dispenses with polarized distinctions of teacher versus learner, and as a result, the classroom becomes a balance of instructional types (with fewer traditional, direct instructional interventions).

Further, facilitation of learning involves a manner of interacting with students that shows care, warmth, optimism, respect, patience, trust, empathy, and acceptance of learners, which also align with Daoist approaches (Cornelius-White \& Harbaugh, 2010; Nagel, 1994).

\subsection{Sharing of Power and Control with Learners}

In learner-centered environments, learners make some of the decisions related to their coursework when feasible (Blumberg, 2009; Cornelius-White \& Harbaugh, 2010). Thus, there is a responsible sharing of power and control with learners, whereby learners exercise some control and independence with regards to their learning processes (Blumberg, 2009; Schweisfurth, 2013; Weimer, 2013). For example, when feasible, learners might be asked to establish assignment deadlines, identify particular assignments or topics to complete, or determine governance or course policies, leading to a more democratic approach (Blumberg, 2009; Minter, 2011; Schweisfurth, 2013). Likewise, in the Tao of Teaching, Nagel encourages teachers to enable students to have power over what they learn and how they learn it (Nagel, 1994). Empowering leaners with choices and responsibility for learning demonstrates trust on the part of the instructor of his/her students (Cornelius-White \& Harbaugh, 2010).

Unfortunately, when instructors attempt to maintain all power and control in the classroom, the authoritarianism tends to reduce the motivation and independence of learners, including taking responsibility for their own learning (Weimer, 2002). In learner-centered classrooms, instructors still make many of the decisions about learning - just not all of them - and instructors often seek student input (Weimer, 2013). Thus, there is a change in the balance of power, with learner-centered environments aiming for responsible and equitable sharing of power and control with learners (Blumberg, 2009; Doyle, 2011; Weimer, 2013). However, incumbent on this is a mature acceptance by learners of ultimate responsibility for their learning (Weimer, 2002). One area in which an instructor in a learner-centered classroom shares power and elicits student input is in evaluation or assessment of student work (Blumberg, 2009). Although such instructors typically assign final grades, they rely on input from self and peer-assessments to complete the evaluation, leading to triangulation, or validation, of the information (Blumberg, 2009).

Thus, responsibly empowering and sharing control with learners with regards to their learning processes can positively 
influence their motivation for and engagement in learning (Doyle, 2011; Weimer, 2013). The sharing of power and control can have such an impact on motivation that its absence is known to stir fear-based anxiety, which can be debilitative (Alpert \& Haber, 1960). Unfortunately, one of the hindrances to attaining student-centeredness is the psychological fear among teachers of sharing their power and authority with students, and underlying this fear is the concern that power-sharing carries with it the potential for disorder in the classroom (Schweisfurth, 2013).

Fortunately, Daoist perspectives are helpful in promoting a sharing of power and control in the classroom, as they are about an acceptance of letting some things go in order to acquire other things. For example, it's analogous to bamboo that grows tall after surviving drenching storms, or water that melodically flows around rocks but dissolves them eventually. Embracing this perspective also helps to harmonize unanticipated classroom occurrences. Lao Tzu described the Daoist leadership style in Chapter 17 in the following way: "The best of all rulers is but a shadowy presence to his subjects... When his task is accomplished and his work done the people all say 'it happened to us naturally"' (Lau, 2009, p. 99).

The Daoist principle of leadership by example is neither haughty nor demanding, as that leads to resentment and rebelliousness (Jeffrey, 2015). It is also not authoritarian and does not insist upon blind obedience, for this reaps only short-term results at the expense of longer term objectives (Jeffrey, 2015). Likewise, in the Tao of Teaching, Nagel states "Wise teachers have authority but do not choose to be authoritarian." (Nagel, 1994, p. 39). Instead, leadership by example embraces appropriate actions with humility and follows through on promises (Jeffrey, 2015). Creating a caring, warm, and trusting atmosphere in which the instructor "walks the walk" in addition to "talks the talk" encourages learners to do the same as part of their learning and development (Cornelius-White \& Harbaugh, 2010).

\subsection{Student Activity and Responsibility for Learning}

Learners are expected to practice their skills and be engaged in their learning in a learner-centered classroom. This translates to instructors "stepping back" and allowing learners to do more tasks in the classroom themselves, such as generating questions and attempting problem solutions on their own (Weimer, 2013). This aligns with the constructivist viewpoint on education, which supports learner-centered practices and maintains that learners must be interacting with and acting upon the content versus just passively receiving it (Benson, 2012; Walczyk \& Ramsey, 2003; Weimer, 2013).

Implicit in this is the viewpoint that learners must take responsibility for and control of their own learning, meaning they must undertake the hard work involved in learning in order to actually learn and be lifelong learners (Benson, 2012; Bishop, 2014; Doyle, 2011; Felder, 2011; Sulla, 2011; Weimer, 2013; Weimer, 2002). Although the instructor is there to guide and facilitate the acquisition of knowledge, it's ultimately up to the student to learn and demonstrate his/her knowledge and skills, and the instructor must allow and enable learners to assume this responsibility (Blumberg, 2009; Weimer, 2013; Weimer, 2002). Thus, active learning is a learner-centered strategy (Altay, 2014; Cornelius-White \& Harbaugh, 2010; Felder, 2011; Weimer, 2013). In the Tao of Teaching, Nagel tells teachers that application and active participation by students is necessary to achieve full learning (Nagel, 1994). In general, active learning is considered "good practice", "quality instruction", and "learner-centered" within undergraduate classrooms (Chickering \& Gamson, 1999; Walczyk \& Ramsey, 2003).

By embracing the Daoist spirit of detachment, instructors are better able to guide learners in their creative discoveries and learning and enhance their awareness of taking responsibility for their own learning. This is in contrast to stifling learners' initiatives through too many directives that can inhibit their assuming of responsibility for learning. Detachment in a Daoist sense is not about indifference or apathy. Instead, it is about being less controlling, thereby allowing for student creativity, participation, and independence (Jeffrey, 2015). In Chapter 9 of the Daode Jing, Lao Tzu said the following related to an instructor "stepping back" and divesting some control to promote learning: "Rather than fill it to the brim by keeping it upright, better to have stopped in time; hammer it to a point, and the sharpness cannot be preserved for ever; there may be gold and jade to fill a hall, but there is none who can keep them. To be overbearing when one has wealth and position, is to bring calamity upon oneself. To retire when the task is accomplished, is the way of heaven" (Lau, 2009, p. 91).

As a current example of this type of learning environment where learners are expected to take responsibility for their learning, language classrooms tend to exhibit learner-centeredness, with most present-day thought and direction about language learning converging on learner-centeredness (Benson, 2012). It is thought to lead to more effective learning for multiple reasons, including sensitivity to individual needs, construction of knowledge and meaning, student participation, and acceptance of personal responsibility for learning (Benson, 2012). Learner-centered teachers consider and accommodate the individual learning differences and styles of their learners by using different methods or offering choices in learning processes (Blumberg, 2009). 


\subsection{Collaboration among Learners as well as Learners and Instructors}

Collaboration and interaction among learners is promoted in learner-centered classrooms, with the belief (backed by evidence) that learners learn from one another (Blumberg, 2009; Doyle, 2011; Weimer, 2013). Furthermore, a learner-centered environment embodies and utilizes cooperation among students and cooperative learning (Chickering \& Gamson, 1999; Walczyk \& Ramsey, 2003). The classroom should not be an arena of win versus loss competition among its members, including between students and the teacher (Nagel, 1994). In Chapter 8 of the Daode Jing, Lao Tzu said the following in relation to collaborative ways: "The highest good is like water. Because water excels in benefitting the myriad creatures without contending with them and settles where none would like to be, it comes close to the way" (Lau, 2009, p. 90).

In Daoist philosophy, the concept of wu-wei encourages acceptance of situations "as they are" (just as water adapts to the shape of its environment), and going with the natural, underlying flow of energy, such that one naturally knows when to "move when it is profitable and to stop when it is not," as with effortless action (Kohn, 2009). Closely associated with wu-wei is ziran, a central concept of Daoism that describes the manner in which nature is uncontentious (Kohn, 2009). Perhaps one of the best descriptions of ziran is in the ancient Chinese saying "Nature never hurries, yet leaves nothing undone." Both wu-wei and ziran are evident when there is an acceptance of unexpected or new circumstances as realities to be embraced. In short, acceptance and practice of the principles of wu-wei and ziran enables one to recognize inherent harmony within an apparently-conflicted or chaotic situation.

In addition, in learner-centered classrooms, there is an appreciation that teachers can learn from learners as part of a mutual, complementary learning community, analogous to the complementary nature of the yin and yang (Weimer, 2013). Student-teacher relationships are aided by teachers who practice "realness" by admitting a mistake and turning it into a learning opportunity, or admitting a lack of knowledge on something (Cornelius-White \& Harbaugh, 2010; Nagel, 1994). Likewise, it is also important for instructors to provide guidance and encouragement during in-class activities, including acknowledgement of student responses (even if vague), as well as circulating among learners to facilitate their work or responses, versus simply standing at the front of the classroom (Cornelius-White \& Harbaugh, 2010).

\subsection{Higher-Order Skills Instruction and Development}

Learner-centered teaching and learning includes explicit instruction in and practice of higher-order thinking skills as well as reflection and metacognition. In learner-centered classrooms, learners learn how to synthesize concepts as well as think critically, including how to evaluate information and analyze and solve problems with instructor guidance (Doyle, 2011; Felder, 2011; Walczyk \& Ramsey, 2003; Weimer, 2013). Also, learners reflect on their learning and knowledge as well as their methods for learning to make themselves more self-directed, self-regulated, lifelong, metacognitive learners (Weimer, 2013; Bishop et al., 2014; Blumberg, 2009).

Since learner-centered classrooms understand the importance of obtaining these skills as well as a deep understanding of the material, content coverage must exist in combination with use of the content, thereby leading to the development of learning skills as well as more sophisticated, discipline-specific skills needed for professional life (Weimer, 2013; Weimer, 2002). Thus, content is applied to develop both a knowledge base as well as the skills needed for deep and lasting learning and understanding, including the ability to learn new content in the future (Weimer, 2013; Blumberg, 2009). This is based in part on the fact that content coverage alone does not enable deep understanding or retention (Weimer, 2013). In contrast, learner-centered instructors aim for deep and lasting learning and understanding of material (Weimer, 2013).

Based on Daoist principles, excess or a lack of simplicity can lead to distress, anxiety, and lost time and energy (Jeffrey, 2015; Nagel, 1994). For example, one may have noticed that trying to cram more into class time results in learners being unable to recall much of it (Jeffrey, 2015). Also, this approach drains energy and diminishes insight into the benefits of learning itself (Jeffrey, 2015; Nagel, 1994). In contrast, for example, encouraging and inspiring more independent study in an area of interest can help learners to go beyond rote learning to be self-reliant, motivated, inquisitive, and growth-oriented (Jeffrey, 2015; Jeffrey, 2019; Nagel, 1994).

Therefore, the application of the concept of "less is more," which aligns with the concepts of wu-wei and ziran, saves time and energy by keeping things simple and therefore allows for higher-order skills instruction and development (Jeffrey, 2015). Mere robotic teaching, including a "my way or the highway" mentality, turns learners off such that they often soon forget the material (Jeffrey, 2015). Believing that a mere dissemination of course content is enough to create deep and lasting learning and understanding can lead to sub-optimal learning (Nagel, 1994). In Chapter 2 of the Daode Jing, Lao Tzu wrote the following related to a "less is more" approach: "The sage keeps to the deed that consists in taking no action and practices the teaching that uses no words" (Lau, 2009, p. 84). Nagel encourages teachers to use their words sparingly, as the instructor is just one among many people in the classroom (Nagel, 1994). 


\subsection{Evaluation for Learning}

In the learner-centered classroom, evaluation is viewed more as a learning activity versus a means to generate course grades, including needed learning in the performance of self and peer-assessments (Bishop et al., 2014; Blumberg, 2009; Minter, 2011; Weimer, 2013; Weimer, 2002). Assessment is both summative and formative, with the latter allowing for improvement via instructor feedback (Blumberg, 2009). Assessment also tends to be more authentic in the learner-centered classroom, resembling what professionals in the field are expected to be able to do (Blumberg, 2009; Walczyk \& Ramsey, 2003). In Chapter 36 of the Daode Jing, Lao Tzu said the following, which can be related to growth-enabling formative assessment and evaluation: "If you would have a thing shrink, you must first stretch it; if you would have a thing weakened, you must first strengthen it; if you would have a thing laid aside, you must first set it up; if you would take from a thing, you must first give to it. This is called subtle discernment: the submissive and weak will overcome the hard and strong..." (Lau, 2009, p. 118).

In our materialistic world, we are conditioned to believe that the more we accumulate, the safer and more satisfied we will be (Jeffrey, 2015). Unfortunately for learners, this applies to grades as well. Such thinking can quickly become addictive and lead to a false sense of security and a struggle to protect what has been accumulated (Jeffrey, 2015). Again, following the principles and concepts of wu-wei and ziran can lead to the realization that evaluation is not a dreaded "be all and end all." Rather, it is a stepping stone along the lifelong path of learning. On this path there is no clearly defined destination except for the path itself, one in which obstacles do not block the way because they are an indispensable part of the path of learning itself. Actually, such obstacles are understood to manifest the seeds of future opportunities. Thus, Daoist principles teach that learners should engage more in the opportunity to learn without the artificial fear of impending grades. This coincides with evaluation not only for the sake of assessment but also for much longer-term and gratifying learning, highlighting the desirability of formative as well as summative assessment.

Related to sharing of power in the classroom and facilitation of learning, learners are in an advantageous position to help evaluate the performances or behaviors of their peers by offering insights that may not have been observable by the instructor (Blumberg, 2009). This is because the learners are in the process of the learning and know the experience firsthand, while the instructor is often a facilitator and onlooker and thus cannot comprehend nor necessarily observe directly the experiences of the learners (Blumberg, 2009). Thus, the role of learners in self and peer evaluations is indispensable in terms of a detailed and firsthand yin perspective, while that of the instructor is equally invaluable from a broader and more holistic yang perspective.

\section{Conclusions: The Effortless Losses that Enable the Positive Gains in LCT}

This paper described the key aspects of learner-centered teaching (LCT) and highlighted their relationship to and alignment with ancient Daoist wisdom and philosophy so as to further support and promote the use of LCT in college classrooms and beyond. The key characteristics of LCT, which are interrelated and interdependent, are as follows: 1) the instructor as a facilitator of learning, 2) sharing of power and control with learners, 3) student participation and responsibility for learning, 4) collaboration among learners, 5) higher-order skills instruction and development, and 6) evaluation for learning purposes.

The sharing of power and control in the classroom, which closely coincides with the wisdom of Daoism, embodies or can lead to trust, mutual respect, motivation and engagement, enhanced assessment and evaluation, student independence, assuming of responsibility for learning, and overall shared dedication to academic achievement (Cornelius-White \& Harbaugh, 2010; Nagel, 1994). Although sharing of power and control with learners may create a sense of loss or uncomfortableness for the instructor, this democratic approach to education aligned with Daoism can create space for the above-mentioned gains to be realized and mutually shared. Additional gains include 1) Moderation, simplicity, and humbleness, 2) harmony in the classroom, 3) mirroring the way of nature that never hurries yet leaves nothing undone, and 4) caring, compassion, and collaboration (Cornelius-White \& Harbaugh, 2010; Jeffrey, 2018; Nagel, 1994).

\section{Acknowledgement}

This work was made possible by the Engineering Education Research Center (EERC) at the University of Pittsburgh and the Sichuan University-Pittsburgh Institute (SCUPI) in Chengdu, China.

\section{References}

Alpert, R., \& Haber, R. (1960). Anxiety in academic situations. Journal of Abnormal and Social Psychology, 6(1), 207-215. https://doi.org/10.1037/h0045464

Altay, B. (2014). User-centered design through learner-centered instruction. Teaching in Higher Education, 19(2), 138-155. https://doi.org/10.1080/13562517.2013.827646 
Bailey, K. (1990). The use of diary studies in teacher education programs. In J. Richards, \& D. Nunan (Eds.), Second Language Teacher Education. United Kingdom: Cambridge University Press.

Bell, J. (1993). Doing your Research Project: a Guide to First Time Researchers in Education and Social Science. Buckingham, United Kingdom: Open University Press.

Benson, P. (2012). Learner-centered teaching. In A. Burns, \& J. Richards (Eds.), The Cambridge Guide to Pedagogy and Practice in Second Language Teaching. New York: Cambridge University Press, pp. 30-37.

Bishop, C., Caston, M., \& King, C. (2014). Learner-centered environments: Creating effective strategies based on learner attitudes and faculty reflection. Journal of the Scholarship of Teaching and Learning, 14(3), 46-63. https://doi.org/10.14434/josotl.v14i3.5065

Blumberg, P. (2009). Developing learner-centered teaching: A practical guide for faculty. San Francisco: John Wiley \& Sons, pp. xix, 3, 73, 101, 104, 108, 116, 128-131, 151, 157, 162-165, 168, 180, 187, 193, 194, 213.

Chickering, A., \& Gamson, Z. (1999). Development and adaptations of the seven principles for good practice in undergraduate education. New Directions for Teaching and Learning, 80, 75-81. https://doi.org/10.1002/t1.8006

Cornelius-White, J., \& Harbaugh, A. (2010). Learner-centered instruction: Building relationships for student success. Thousand Oaks, CA: Sage Publications, pp. 33-38, 41, 49, 63, 78.

Doerger, D. (2004). The teacher as Taoist. Essays in Education. Aiken: University Of South Carolina Press.

Doyle, T. (2011). Learner-centered teaching: Putting the research on learning into practice. Sterling, VA: Stylus Publishing, LLC, pp. 1-7.

Felder, R. (2011). Random thoughts... Hang in there! Dealing with student resistance to learner-centered teaching. Chemical Engineering Education, 45(2), 131-132.

Flowers, J. (1998). Problem solving in technology education: a Taoist perspective. Journal of Technology Education, 10(1), 20-26. https://doi.org/10.21061/jte.v10i1.a.2

Henderson, M., Morris, L., \& Fitz-Gibbon, C. (1987). How to Measure Attitudes. United Kingdom: Sage Publications.

Howell-Richardson, C., \& Parkinson, B. (1988). Learner diaries: Possibilities and pitfalls. In P. Grunwell (Ed.), Applied Linguistics in Society. London: CILT/BAAL, pp. 74-79.

Jarvis, J. (1992). Using diaries for teacher reflection on in-service courses. English Language Teaching Journal, 46(2), 133-143. https://doi.org/10.1093/elt/46.2.133

Jeffrey, D. (2015). Daoist wisdom for teachers: A diary study. Journal of Daoist Studies, 8, 152-164. Retrieved from: https://doi.org/10.1353/dao.2015.0007

Jeffrey, D. (2018). A perspective of democratic teaching through the lens of research on the application of Daoism. Other Education: The Journal of Educational Alternatives, 7(1), 68-70. Retrieved from: https://www.othereducation.org/index.php/OE/article/view/210.

Jeffrey, D. (2019). Zhuangzi in the classroom: A teacher diary study. Journal of Daoist Studies, 12, 211-224.

Kohn, L. (2009). Being at one with heaven and earth: the ethical integration of self, society, and nature in Daoism. Journal of Law, Philosophy and Culture, 3(1), pp. 365-384. Lau, D. (2009). Tao Te Ching. Suffolk: Penguin Books.

Minter, M. (2011). Learner-centered (LCI) vs. teacher-centered (TCI) instruction: A classroom management perspective. American Journal of Business Education, 4(5), 55-62. https://doi.org/10.19030/ajbe.v4i5.4225

Nagel, G. (1994). The Tao of Teaching. New York: Donald I. Fine, Inc., pp. 1-2, 6, 13, 21, 23, 39, 61, 63, 71, 83, 89-90, 95, 99, 101, 114, 145, 153, 195, 203, 209.

Nunan, D. (1992). Research Methods in Language Learning. United Kingdom: Cambridge University Press.

Richards, J., \& Lockhart, C. (1996). Reflective Teaching in Second Language Classrooms. Cambridge: Cambridge University Press.

Schweisfurth, M. (2013). Learner-centred education in international perspective: Whose pedagogy for whose development? London: Routledge, pp. 12-13, 20.

Serran-Pagan y Fuentes, C. (2017). The coincidence of opposites in Thomas Merton and Zhuangzi: A case study on how professors can effectively use the language of paradoxes in the classroom at the university level. Journal of Education in Contexts, 1(7), 84-116. 
Sulla, N. (2013). Students taking charge: Inside the learner-active, technology-infused classroom. Larchmont, NY: Eye on Education, pp 139-140. https://doi.org/10.4324/9781315855400

Walczyk, J., \& Ramsey, L. (2003). Use of learner-centered instruction in college science and mathematics classrooms. Journal of Research in Science Teaching, 40(6), 566-584. https://doi.org/10.1002/tea.10098

Weimer, M. (2018). Is My Teaching Learner-Centered. Retrieved from https://www.facultyfocus.com/articles/teaching-professor-blog/teaching-learner-centered/

Weimer, M. (2002). Learner-centered teaching: Five key changes to practice. San Francisco: John Wiley \& Sons, pp. xvi-xix, 125.

Weimer, M. (2012, August 8). Five Characteristics of Learner-Centered Teaching. Retrieved from https://www.facultyfocus.com/articles/effective-teaching-strategies/five-characteristics-of-learner-centered-teachin g/

Weimer, M. (2013). Learner-centered teaching: Five key changes to practice. San Francisco: John Wiley \& Sons, pp. $10-11,13-15,24,60,63,72,77,81,83-84,94,113,119,123-126,167,169$

\section{Copyrights}

Copyright for this article is retained by the author(s), with first publication rights granted to the journal.

This is an open-access article distributed under the terms and conditions of the Creative Commons Attribution license which permits unrestricted use, distribution, and reproduction in any medium, provided the original work is properly cited. 